\title{
EL LATÍN DE HISPANIA A PARTIR DE LAS INSCRIPCIONES EN VERSO. GRAFÍAS, VOCALISMO Y DIPTONGOS
}

\author{
Lidia Martín Adán \\ Universidad de Sevilla \\ lydiama85@gmail.com

\begin{abstract}
LATIN FROM VERSE INSCRIPTIONS IN HISPANIA.
\end{abstract} \\ GRAPHICAL SYMBOLS, VOCALISM AND DIPHTHONGS
}

RESUMEN: El trabajo pretende ofrecer una actualización y sistematización de los principales fenómenos gráficos y vocálicos presentes en las inscripciones en verso de Hispania.

PALABRAS CLAVE: Epigrafía latina, lingüística latina, latín vulgar, Hispania.
ABSTRACT: This essay offers an updated and a systematization of the main graphic and vocalic phenomena found in verse inscriptions from Hispania.

KEYWORDS: Latin Epigraphy, Latin Linguistics, Vulgar Latin, Hispania.

RECIBIDO 18.09.2013. ACEPTADO: 30.03.2014

\section{INTRODUCCIÓN}

Para llevar a cabo nuestro propósito hemos realizado un análisis minucioso de todos los $C L E$ hispanos hallados hasta la fecha, concretamente 247, recogidos en el portal www.clehispaniae.com ${ }^{1}$.

${ }^{1}$ Este portal es fruto del proyecto de investigación Inscripciones latinas en verso de Hispania. Tratamientos multimedia para la investigación y su transferencia, en el que se enmarca el trabajo que presentamos. Este proyecto ha estado integrado por el equipo de redacción del fascículo 2 del volumen XVIII del Corpus Inscriptionum Latinarum, destinado a incluir toda la poesía epigráfica de Hispania, organizada según la geografía administrativa del Imperio Romano. Asimismo la autora pertenece a un grupo de investigación inserto en el PAIDI, código HUM-156. 
Dos obras fundamentales constituyen la base de este estudio: Le latin d'Espagne d'après les inscriptions. Étude linguistique (1906), de A. J. Carnoy, e Inscripciones hispanas en verso (1952), de S. Mariner. La primera presenta un panorama claro del latín de Hispania a partir de los materiales epigráficos conocidos hasta entonces. Carnoy ofrece una enumeración de los ejemplos hallados de cada fenómeno fonético y morfológico atendiendo especialmente a su cronología y su distribución geográfica, y realiza a partir de esta enumeración un comentario sobre los mismos. Mariner, por su parte, presenta un análisis gramatical, métrico y literario de los CLE hispanos conocidos hasta ese momento con el objetivo primordial de estudiar la evolución desde la métrica cuantitativa hacia la métrica acentual en Hispania a partir de las inscripciones.

Sin embargo, desde la publicación de la señera obra de Mariner, no ha vuelto a realizarse un estudio de la lengua de las inscripciones en verso de Hispania, a pesar de que en los últimos años han aumentado de forma espectacular los testimonios conocidos: Mariner trabajó con 119 inscripciones mientras que actualmente conocemos 247. Además, a partir de la observación directa del soporte, se han realizado nuevas lecturas de epígrafes ya estudiados, se han clasificado como carmina epígrafes que en su día no fueron considerados como tal, o viceversa, y, en definitiva, se ha producido un auge en el estudio de los CLE, que ha permitido profundizar en todos los aspectos de los mismos.

Así pues, nos ha parecido conveniente revisar y actualizar ciertos aspectos lingüísticos presentes en estas inscripciones, sirviéndonos de un material mucho más amplio del que manejaba Mariner, con nuevas ediciones de epígrafes y estudio exhaustivo de los mismos ${ }^{2}$.

\section{GrafíAs}

\subsection{Representación de $\bar{\imath}$ mediante $e i^{3}$}

A lo largo de la historia del latín se intentaron establecer diferentes procedimientos para indicar gráficamente la cantidad larga de una vocal: la geminación (ss. II-I a. C.), la utilización del dígrafo ei, y en menor medida ou, para representar respectivamente una $\bar{l}$ y una $\bar{u}$ procedentes de la monoptongación de estos diptongos (s. II a. C.); el ápice (s. I a. C.) y, por último, la I longa.

\footnotetext{
${ }^{2}$ Las inscripciones aparecen nombradas con el código utilizado en C. Fernández Martínez, J. Gómez Pallarès, J. del Hoyo Calleja (eds.), Carmina Latina Epigraphica Hispaniae. Portal de poesía epigráfica latina: búsquedas icónicas y textuales. A este portal se puede acceder en www.clehispaniae. com, mediante un código que se obtiene de forma automática a través de la identificación del investigador. Se trata de una publicación protegida con una licencia de creativecommons.org. Hasta el momento es la edición más actualizada y procedente de la observación directa de los textos siempre que estos se conserven. La correspondencia con otras colecciones epigráficas puede consultarse más abajo.

${ }^{3}$ Sobre este fenómeno: Mariner 1952: 3-10; Leumann 1977: $\S \S 12-14$; Bassols 1981: $\S 60$.
} 
En los CLE de Hispania conocidos no aparece ningún ejemplo de geminación; sin embargo, sí tenemos numerosos ejemplos de la utilización del dígrafo ei para la representación de una $\bar{\imath}$ procedente de diptongo, así como del uso del ápice y la I longa.

Contamos concretamente con 25 ejemplos del más antiguo de estos procedimientos, el uso del dígrafo ei, repartidos en $11^{4}$ inscripciones. De ellas, ocho pertenecen a la provincia Tarraconense (T8, T24, V4, MU3, MU12, MU13, MU13B, MU20), dos a la Bética (J7 y CA8) y una a la Lusitania (CAS1).

Desde el punto de vista cronológico, estas inscripciones pertenecen al período comprendido entre el s. I a. C. y el s. I d. C. Las más tardías parecen ser las pertenecientes a la Bética, CA8 y J7, ya que la presencia de la muy característica fórmula gaditana cara suis $^{5}$ en la primera, y la fórmula de consagración a los dioses Manes en la segunda, invitan a situarlas a finales del s. I o comienzos del s. II d. C.

En algunas de estas inscripciones el dígrafo ei se combina con la I longa o el ápice. Concretamente, se encuentran I longas en las dos inscripciones de la Bética, CA8 y J7, y en dos de la Tarraconense: T8, perteneciente al último tercio del s. I d. C., y V4, de principios del s. I d. C. Se trata, por tanto, exceptuando a V4, de inscripciones tardías, que reflejarían la transición entre ambos procedimientos. Por su parte, el ápice aparece en MU13 (mediados del s. I a. C.) para marcar alguna $\bar{u}$ y $\bar{a}$, pero no se emplea de manera sistemática.

Mariner $^{6}$ señala la posibilidad de que el empleo del dígrafo ei en nuestras inscripciones responda a una regla ortográfica, según la cual se utilizaría dicho dígrafo únicamente para marcar la $\bar{l}$ etimológica de una terminación flexiva, tendencia propugnada por algunos gramáticos como Lucilio o Quintiliano. En efecto, los ejemplos que las inscripciones hispanas en verso nos ofrecen apoyan esta teoría, pues en la mayoría de las inscripciones el dígrafo se da sólo en terminaciones flexivas ${ }^{7}$.

Hay, no obstante, algunos casos en los que no se cumple dicha tendencia. En la inscripción MU12 ${ }^{8}$ (s. I a. C.) hallamos seis, subjuntivo del verbo sum, donde

\footnotetext{
${ }^{4}$ Mariner recoge seis de estas: T24, V4, CA8, MU3, MU13 y MU20. Además incluye CIL 02, 03504 que ha sido desechada de nuestro corpus por no tratarse de una inscripción en verso.

${ }^{5}$ Cf. Stylow 1995: 223.

${ }^{6}$ Mariner 1952: 5-6.

${ }^{7}$ Dativos-ablativos plurales: lacrumeis y heis (MU13, s. I a. C.), nobeis (V4, s. I), officie[is] (T24, s. I), robusteis (MU20, s. I) y sueis (CA8, ss. II-III). Nominativos plurales: quei (T8, s. I), quietei (CAS1, s. I) y tractatei (J7, ss. I-II). Antiguos locativos de tema en -o / -e adverbializados: heic (MU12 y MU13, s. I a. C., T24, MU3 y CAS1, s. I), sei (MU13B, s. I a. C.y MU3, s. I) y seic (MU20, s. I). Primera persona singular del pretérito perfecto: uixei y potuei (MU13B, s. I a. C.) y tulei (CAS1, s. I).

${ }^{8}$ Mariner (1952: 6) hace referencia a esta inscripción considerándola no métrica, sin embargo ha sido incluida en nuestro corpus como una composición commatica, pues es posible distinguir en ella varias secuencias métricas.
} 
el diptongo no es etimológico. Esta grafía puede achacarse aquí al parecido con los antiguos locativos adverbializados sei y seic, donde el diptongo sí es etimológico. En MU13B (s. I a. C.), inscripción hallada con posterioridad a la obra de Mariner, el uso del dígrafo ei en la desinencia de la primera persona singular del pretérito perfecto de indicativo es sistemático, exceptuando fui. Tampoco conocía Mariner la inscripción T8, donde el dígrafo es utilizado a veces en sílabas no desinenciales (eiras y deicas) y, sin embargo, no aparece en el ablativo uotisque. La vacilación en esta inscripción, donde, como se señaló supra, también se dan tres casos de I longa (íamque, ín y síc), puede deberse a que pertenece a una época más tardía (finales del s. I d. C.), en la que la utilización del dígrafo no respondía ya a esa tendencia.

La inscripción $\mathrm{J}^{9}$, no incluida en la obra de Mariner, es de transmisión manuscrita y de estado muy fragmentario, por lo que hay que ser cautelosos a la hora de extraer conclusiones a partir del texto transmitido. De acuerdo con la edición de Jimena, el texto recoge la forma tractatei, que podría ser el nominativo plural del participio tractatus. El resto de las $\bar{l}$ del texto, sean desinenciales o no, aparecen sin marca o como I longa, vacilación atribuible nuevamente a la época tardía de la inscripción (finales del s. I - principios del s. II). Lo mismo ocurre en la otra inscripción bética, CA8, de la misma época que la anterior, que presenta vacilaciones en la $\bar{l}$ desinencial, pues aparece el dígrafo ei en el ablativo sueis pero I longa en uíxi y superí.

En líneas generales, por tanto, podemos decir que la representación de la $\bar{l}$ mediante el dígrafo ei se da en las inscripciones hispanas en verso entre el s. I a. C. y el s. I d. C., especialmente en la provincia Tarraconense (un $73 \%$ de los casos pertenecen a esta provincia, frente al $18 \%$ de la Bética y el $9 \%$ de la $\mathrm{Lu}-$ sitania). Su uso responde, en la mayoría de los casos, a la tendencia de la época consistente en restituir el diptongo en las desinencias donde era originario: de los 25 casos con los que contamos solo tres constituyen una excepción a esta regla.

\subsection{Grafías para $y^{10}$}

En un principio, la $v$ de los préstamos griegos, equivalente fonéticamente a $\ddot{u}$, se transcribía en latín como $u$. Sin embargo, en el s. I a. C. se introduce en el alfabeto latino la letra $y$, considerándose más culta la utilización de esta grafía. No obstante, en la lengua popular, esta grafía fue sustituida en numerosas ocasiones por $i$.

\footnotetext{
${ }^{9}$ CLEBES: $133-138$.

${ }^{10}$ Sobre estas grafías: Grandgent 1991: §187; Moralejo 1972; Leumann 1977: §52 y §85; Bassols 1981: §59; Väänänen 1985: §58.
} 
En la siguiente tabla puede observarse el número de ejemplos presentes en los $C L E$ de Hispania de cada una de las grafías y su distribución cronológica.

\begin{tabular}{|l|c|c|c|c|c|c|c|c|c|}
\cline { 2 - 10 } \multicolumn{1}{c|}{} & s. I a. C. & s. I & s. II & s. III & s. IV & s. VI & s. VII & s. d. ${ }^{11}$ & Total \\
\hline Grafía $u$ & 1 & 1 & 2 & \multicolumn{7}{c|}{-} & 4 \\
\hline Grafía $y$ & - & 3 & 4 & 1 & 1 & 1 & 1 & 3 & 14 \\
\hline Grafía $i$ & \multicolumn{8}{|c|}{-} & \multicolumn{3}{|c|}{4} & - & 4 \\
\hline
\end{tabular}

Como puede observarse, en los CLE de Hispania predomina la grafía culta $y$ (aparece en un $64 \%$ de los casos, frente al $18 \%$ de $u$ y de $i$ ), de la que tenemos ejemplos a partir del s. I d. C. Encontramos la grafía antigua, $u$, en tres inscripciones del Conuentus Carthaginiensis: una de la primera mitad del s. I a. C.

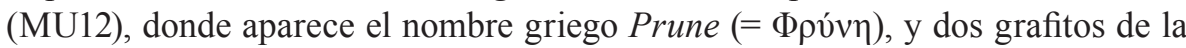
Cueva Negra de los ss. I-II d. C., MUCN10, con numpharum, y MUCN14, donde encontramos Phrugia. Contamos con un caso curioso de transición entre la antigua grafía $u$ y la culta $y$ en una inscripción de la Bética, SE9, fechada en el s. II

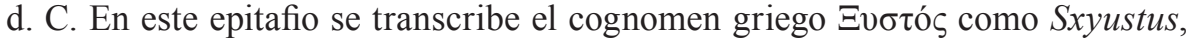
es decir, empleando juntas las dos grafías posibles. La grafía $i$ es escasa en nuestro corpus, únicamente la hallamos en dos términos del latín cristiano, limfa (V6 y SE28) y martir (V6 y BA7), que aparecen en tres inscripciones de época muy tardía (ss. VI-VII).

\subsection{Grafías para aspiradas griegas ${ }^{12}$}

La lengua latina no conservó las oclusivas aspiradas indoeuropeas, que sí sobrevivieron en la lengua griega. La adaptación de estos fonemas en los préstamos del griego se produjo de diferente manera según las épocas. En un principio, estos fonemas fueron sustituidos por las oclusivas sordas correspondientes $(p, t, c)$. Sin embargo, a mediados del s. II a. C., comenzaron a emplearse las grafías $p h$, th y $c h$, imponiéndose definitivamente a principios del s. I a. C. Caso especial es el de la $\varphi$ griega, que se había convertido en fricativa desde antes del s. I d. C., transcribiéndose también a partir de entonces por la $f$ latina (aunque la grafía $p h$ fue siempre considerada la transcripción más correcta). No obstante, en el habla popular, y en consecuencia en las lenguas romances, no llegó a imponerse en la grafía esta aspiración, sustituyéndose la mayoría de las veces por las oclusivas simples.

${ }^{11}$ Sin datación.

${ }^{12}$ Sobre estas grafías: Grandgent 1991: §§ 332-334; Leumann 1977: §§ 165-166; Bassols 1981: $\S \S$ 231-232; Väänänen 1985: §§ 102-103; Purnelle 1989 y 1995. 
A mediados del s. II a. C. empieza a utilizarse la aspiración de oclusivas en algunas palabras de origen latino ("hipergrecismos"), especialmente en nombres propios, como Gracchus, pero también en sustantivos comunes como lachrima o sepulchrum ${ }^{13}$. Generalmente se trata, como en estos casos, de oclusivas próximas a líquidas y vibrantes.

En los CLE de Hispania predomina la grafía culta para las tres aspiradas. En el caso de la aspirada labial únicamente encontramos la grafía de la oclusiva sorda en dos nombres propios: Prune y Tropimus, el primero perteneciente a una inscripción de Carthago Noua del s. I a. C. (MU12) y el segundo, a una de Toledo más tardía, de los ss. II-III (TO3). La grafía culta es la que se utiliza en la mayoría de los casos $(59 \%)^{14}$, pertenecientes fundamentalmente a inscripciones datadas entre los Ss. I-III; sólo un ejemplo (aunque hay que tener en cuenta que no es posible datar el ejemplo presente en la inscripción SE15, de transmisión manuscrita) sobrepasa estos límites cronológicos, scyphus, de BRA2 (s. VI).

La grafía $f$ aparece en cinco casos (29\%), dos fechados entre los ss. II y III, Diofanis (T7) y orfanus (T3), y tres más tardíos, de los ss. VI y VII, epitafion (BRA3), limfam (V6) y limfa (SE28).

En cuanto a la aspirada gutural, en un $73 \%$ de los términos se utiliza la grafía culta ${ }^{15}$; sólo en algunas palabras del latín cristiano pertenecientes a inscripciones muy tardías (ss. VI-VII) hallamos la grafía $c$ : Cristi, que aparece en tres inscripciones (BA18, s.V; CO5, ss. VI-VII, y CO18, s. VII), monacos (V6, s. VI), monacis (T18, s. VI) y, por último, crismate, que aparece en SE28 (ss. VI-VII), inscripción que presenta, en cambio, la grafía culta en los términos Christi y choris.

Para transcribir la aspirada dental también se utiliza en la mayoría de los casos $(60 \%)$ la grafía culta ${ }^{16}$. La inscripción MU7, del s. I a. C., es una buena muestra de la vacilación existente en esa época a la hora de representar estos fonemas, pues el cognomen del difunto aparece con $t$ en el praescriptum (Torax) y con th en el carmen (Thoracis). El otro ejemplo de la utilización de la oclusiva sorda es también un nombre propio, Antisporus, que aparece dos veces en una inscripción de Cástulo del s. I (J5). En cambio no contamos, al contrario de lo que ocurría con la gutural, con ejemplos tardíos de la utilización de esta grafía.

${ }^{13}$ Cf. Bassols 1981: $§ 232$.

${ }^{14}$ numpharum (MUCN10 y MUCN13, s. I), nymphis y Paphien (MUCN11, s. I), Philocalo (MU8, ss. I-II), Phrugia (MUCN14, ss. I-II), Sphr[---] (A1, ss. I-II), Carpophorus (CO7, ss. II-III), scyphus (BRA2, s. VI) y Epaphroditi (SE15, sin datación).

${ }^{15}$ Acheruns (MU13, s. I a. C.), chelys (HU3, s. I), Inachus (BE1, c. s. I), Clearchus (T6, s. II), Eutycheti (T7, s. II), Baccho (MUCN37, ss. II-III), Bacchi (BA18, s. V), Christi (T18, BRA3 y BRA4, s. VI, y SE28, ss. VI-VII), Christus (CO5, ss. VI-VII) y choris (SE28, ss. VI-VII).

${ }^{16}$ Thoracis (MU7, s. I a. C), Diopithes (CA13, ss. II-III), Lethes (T11, s. IV), aetherios (T26, s.IV), aetheria (BA18, s.V) y etheriae (CU3, s. VI). 
En BA18, inscripción datada en torno al s. V, se encuentra el término acleta $^{17}$, donde parece que se ha producido un reemplazo del grupo $t h l$ por $k l$, frecuente en latín vulgar ${ }^{18}$.

En cuanto a "hipergrecismos", contamos en nuestros CLE con dos términos latinos a los que se les añade la aspiración con muchísima frecuencia: sepulchro en lugar de sepulcro (en la inscripción T7 del s. II) y lachrimas por lacrimas (en L1, de los ss II-III).

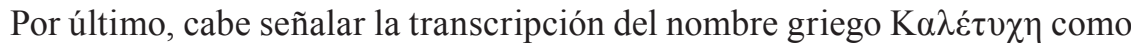
Calethyce en lugar del esperado Caletyche $e^{19}$, en una inscripción de tradición manuscrita de la Bética (SE2), que podría constituir un ejemplo más de la enorme vacilación existente a la hora de representar estos fonemas griegos, aunque esta metátesis de la aspiración puede deberse a un simple error del lapicida o del $\operatorname{copista}^{20}$.

En la siguiente tabla ofrecemos una recapitulación de las diferentes grafías que aparecen en los CLE de Hispania a lo largo de los siglos.

\begin{tabular}{|c|c|c|c|c|c|c|c|c|c|c|c|}
\hline & & & & & & & & & & \\
\hline & & s. I a. C. & s. I & s. II & s. III & s. IV & s. V & s. VI & s. VII & s. d. & Total \\
\hline \multirow{3}{*}{$\begin{array}{l}\text { Grafías } \\
\text { para } \varphi\end{array}$} & $p$ & 1 & - & \multicolumn{2}{|c|}{1} & \multicolumn{5}{|c|}{ - } & 2 \\
\hline & $p h$ & - & 5 & 2 & 1 & \multicolumn{2}{|c|}{ - } & 1 & - & 1 & 10 \\
\hline & $f$ & - & & \multicolumn{2}{|c|}{2} & \multicolumn{2}{|c|}{ - } & \multicolumn{2}{|c|}{3} & & 5 \\
\hline \multirow{2}{*}{$\begin{array}{c}\text { Grafías } \\
\text { para } \chi\end{array}$} & $c$ & \multicolumn{5}{|c|}{ - } & 1 & \multicolumn{2}{|c|}{5} & - & 6 \\
\hline & ch & 1 & 2 & 2 & 1 & - & 1 & \multicolumn{2}{|c|}{6} & - & 13 \\
\hline \multirow{3}{*}{$\begin{array}{c}\text { Grafías } \\
\text { para } \theta\end{array}$} & $t$ & 1 & 2 & \multicolumn{7}{|c|}{-} & 3 \\
\hline & th & 1 & - & \multicolumn{2}{|c|}{1} & 2 & 1 & 1 & \multicolumn{2}{|c|}{ - } & 6 \\
\hline & $\mathrm{c}$ & \multicolumn{5}{|c|}{ - } & 1 & \multicolumn{3}{|c|}{ - } & 1 \\
\hline
\end{tabular}

\footnotetext{
${ }^{17}$ Este término aparece en otras inscripciones cristianas como CIL 06, 10154 (s. IV), donde hallamos aclethico y acletarum.

${ }^{18}$ Cf. Väänänen 1985: $§ 187$.

${ }^{19}$ En otra inscripción de la Bética, $C I L \mathrm{II}^{2} / 7454$ (s. I), puede leerse la forma correctamente grabada. Esta vacilación se da también en el nombre simple Tyche, apareciendo la forma Thyce en algunas inscripciones, como CIL II, 1740 (s. I), perteneciente al Conuentus Gaditanus, o CIL II $2 / 5424$ (s. I), del Conuentus Astigitanus.

${ }^{20}$ Mariner 1952: 50.
} 


\section{Vocalismo simple}

\subsection{Confusiones entre $\breve{l} \mathrm{y} \bar{e}^{21}$}

En latín, la diferencia entre la pronunciación de una $\breve{l}$ abierta y una $\bar{e}$ cerrada era mínima. La paulatina pérdida del valor fonológico de la cantidad a favor del timbre hizo que ambos fonemas, en posición tónica, acabaran confluyendo, en la mayoría de las lenguas romances, en uno solo: una e cerrada. En posición átona, donde las sílabas son pronunciadas con menor esfuerzo, tanto la $\breve{l}$ como la $\breve{e}$ y la $\bar{e}$ confluyeron en una sola $e$.

La pérdida de la cantidad fue más rápida en las sílabas no acentuadas: los primeros ejemplos de vacilación entre $\breve{\imath}$ y $\bar{e}$ en sílaba átona se remontan al s. I d. C., siendo ya completa esta confusión en los ss. III-IV. Las sílabas tónicas se mostraron más resistentes, manteniéndose generalmente las distinciones de cualidad, resultantes de la cantidad originaria, hasta los ss. IV-V, aunque los primeros ejemplos de confusión se remontan al s. $\mathrm{II}^{22}$.

En las sílabas finales las confusiones entre $\breve{l}$ y $\bar{e}$ se vieron favorecidas por las fluctuaciones que se producían, ya desde el latín clásico, entre la $2^{\mathrm{a}}$ conjugación $(-\bar{e} r e)$ y la $3^{\mathrm{a}}(-\breve{e r} e)^{23}$. En los CLE de Hispania el mayor número de confusiones se da en esta posición (13 casos) y más de la mitad se produce en formas verbales de la $2^{\mathrm{a}}$ y $3^{\mathrm{a}}$ conjugación. Mariner ${ }^{24}$ señala que la grafía inversa, es decir $i$ en lugar de $e$, se da solo en casos en que pudo apoyarla una contaminación morfológica: de conjugaciones, en iacis (MU8, ss. I-II) y lugit (CO21B, s. VII), y de terminaciones de nominativo, en antestis ${ }^{25}$ (V6 y CU3, s. VI). A estos ejemplos cabría añadir los nominativos Diofanis (T7, s. II) y sedis (VIS2, ss. III-IV), no recogidos en la obra de Mariner, que apoyarían su teoría.

No obstante, lo mismo puede decirse de la grafía acomodada a la pronunciación, e en lugar de $i$, pues contamos con cuatro formas en las que pudo influir una contaminación entre la $2^{\mathrm{a}}$ y la $3^{\mathrm{a}}$ conjugación: leges (CO12 y BA15, s. II), releges (CO13, ss. II-III), resistes (T3, ss. II-III) y petet (CO75, s. VII), y un nominativo en -es en lugar de -is, tristes (T15, ss. V-VI). Por último, contamos con un ejemplo de confusión de $e$ por $i$ en la desinencia de $2^{\text {a }}$ persona del plural del subjuntivo del verbo sum, sites por sitis, en CO19 (ss. IV-V).

El ejemplo más antiguo de nuestros carmina se encuentra en MU8, iacis por iaces, inscripción datada entre la segunda mitad del s. I y la primera del s. II, pero la mayoría se enmarcan entre los ss. II y III. En cuanto a la zona, el mayor

${ }^{21}$ Sobre este fenómeno: Carnoy 1983: §§ 2-4; Grandgent 1991: §§ 173-174, 197, 201 y 243-244; Mariner 1952: 18-24; Leumann 1977: §57; Bassols 1981: §161; Väänänen 1985: §§ 54-56.

${ }^{22}$ Bassols 1981: $\$ 161$.

${ }^{23}$ Cf. Grandgent 1991: §399; Leumann 1977: §411.

${ }^{24}$ Mariner 1952: 20.

${ }^{25}$ Mariner incluye también el nominativo uatis, perteneciente a la inscripción B 720, desechada en nuestro corpus por estar fuera de la cronología del CIL (hasta el 711). 
número de ejemplos se concentra en la Tarraconense $\left(\operatorname{sei}^{26}\right)$, seguida de la Bética $\left(\operatorname{cinco}^{27}\right) \mathrm{y}$, con tan sólo dos ${ }^{28}$ casos, la Lusitania.

Desde el punto de vista prosódico, Mariner infiere a partir de los ejemplos que maneja que la $e$ abierta resultante era siempre breve ${ }^{29}$. De los ejemplos presentes en las inscripciones halladas con posterioridad a la obra de Mariner, sites (por sitis), en CO19, apoyaría su teoría, pues la $e$ final es escandida como breve; en cambio, en sedis (por sedes), de VIS2, la $i$ se escande como larga.

Mucho más escasos y tardíos son los ejemplos con los que contamos de confusiones en sílaba tónica: uno de $i$ por $e$, accipit ${ }^{30}$ por accepit, en una inscripción de la Bética (SE29) que puede datarse entre los ss. V y VII, y tres de $e$ en lugar de $i$ pertenecientes al s. VI, antestis por antistes (V6 y CU3), cambio frecuente y que puede considerarse también como una metátesis ${ }^{31}$, y meserum por miserum (CU3).

Por último, contamos con tres ejemplos en sílaba pretónica, dos de $e$ por $i$, credetur por creditur y tegetur por tegitur, pertenecientes a una inscripción de Segóbriga del s. VI (CU3), y uno de $i$ por $e$, sedito por sedeto, de una inscripción de la Tarraconense datada entre los ss. IV-V (B2b, 2). Se trata, por tanto, de ejemplos tardíos, todos ellos formas verbales, en los que pudo influir más un cambio de conjugación que una confusión fonética.

Se ajustan, en definitiva, los ejemplos presentes en nuestros carmina a lo ya postulado anteriormente sobre las confusiones entre $\bar{e}$ e $\breve{l}$, al ser mucho más frecuentes y tempranos en sílaba final, donde se unían las vacilaciones morfológicas a la confusión fonética, que en las otras posiciones, tónica y pretónica. En la siguiente tabla puede observarse la distribución cronológica de los ejemplos con los que contamos en cada una de las posiciones.

\begin{tabular}{|c|c|c|c|c|c|c|c|c|c|}
\hline & & & & & & & & \\
\hline & & s. I & s. II & s. III & s. IV & s. V & s. VI & s. VII & Total \\
\hline \multirow{2}{*}{ Sílaba final } & $e$ por $i$ & - & \multicolumn{2}{|c|}{4} & 1 & \multicolumn{2}{|c|}{1} & 1 & 7 \\
\hline & $i$ por $e$ & \multicolumn{2}{|c|}{2} & \multicolumn{2}{|c|}{1} & - & 2 & 1 & 6 \\
\hline \multirow{2}{*}{ Sílaba tónica } & $e$ por $i$ & \multicolumn{4}{|c|}{-} & - & 3 & - & 3 \\
\hline & $i$ por $e$ & \multicolumn{4}{|c|}{-} & \multicolumn{3}{|c|}{1} & 1 \\
\hline \multirow{2}{*}{ Sílaba pretónica } & $e$ por $i$ & \multicolumn{4}{|c|}{-} & - & 2 & & 2 \\
\hline & $i$ pore & \multicolumn{3}{|c|}{-} & \multicolumn{2}{|c|}{1} & \multicolumn{2}{|c|}{-} & 1 \\
\hline
\end{tabular}

${ }^{26} \mathrm{~B} 2 \mathrm{~b}, \mathrm{CU} 3, \mathrm{~T} 3, \mathrm{~T} 7, \mathrm{~T} 15$ y MU8.

${ }^{27} \mathrm{CO} 12, \mathrm{CO} 13, \mathrm{CO} 19, \mathrm{CO} 21 \mathrm{~B}$ y $\mathrm{CO} 75$.

${ }^{28}$ BA15 y VIS2.

${ }^{29}$ Mariner 1952: 20.

${ }^{30} \mathrm{La} i$ es escandida como larga, lo que hace preferible entender que se trata de una confusión entre la $\check{l}$ y $\bar{e}$, y no de un uso de presente por perfecto.

${ }^{31}$ Carnoy 1983: 25. 


\subsection{Confusiones entre $\breve{u}$ y $\bar{o}^{32}$}

Al igual que la $\check{l}$ y la $\bar{e}$ latinas dieron como resultado, en la mayoría de las lenguas romances, una $e$, la $\breve{u}$ y la $\bar{o}$ acabaron confluyendo en una $o$ en la mayor parte del Imperio. No obstante, la confusión entre estos dos fonemas se produjo algo más tarde, en torno al s. IV d. C., en el caso de las sílabas tónicas, y un poco antes, en el caso de las átonas.

De acuerdo con los datos recogidos por Carnoy $^{33}$, los primeros ejemplos hispanos de confusión entre $u$ y $o$ en sílaba final datan del s. II d. C. En cuanto a la zona, esta vacilación no se daría en el centro y norte de Hispania, hecho que todavía es observable en el bable o dialecto asturiano, que mantiene diferenciadas la $u$ y la $o$ final.

No obstante, el primer ejemplo que se da en los CLE de Hispania conocidos pertenece a una inscripción del conuentus Asturum, LE6, hallada en 1950 -y por tanto no incluida en la obra de Carnoy- y datada en el s. III. En esta inscripción encontramos luctos en lugar de luctus, que parece ser una confusión morfológica entre la $4^{\mathrm{a}}$ y la $2^{\mathrm{a}}$ declinación, más que una confusión fonética.

Lo mismo cabe decir de los otros dos casos con los que contamos: arcos por arcus en BA13 (s. V) y curso por cursu en TO5 (s. VII). Se trata de inscripciones pertenecientes a una fecha tardía en la que la cantidad ya se había perdido y las confusiones entre ambas formas se deben a la absorción de los sustantivos de la $4^{\mathrm{a}}$ declinación por parte de la $2^{\mathrm{a}}$. Por tanto, no contamos en nuestro corpus con ningún caso de confusión de $u$ y $o$ en sílaba final que pudiera ser clasificada como puramente fonética.

Los ejemplos de esta confusión en sílaba tónica son escasos y tardíos en los CLE de Hispania. Encontramos dos casos de $o$ por $u$ en la inscripción CU3 (s. VI), tomolo $^{34}$, donde también se produce la confusión en sílaba postónica, y sobitus, y uno de $u$ por $o$, octubres ${ }^{35}$, en CO21B, inscripción del s. VII. Si bien, hay que tener en cuenta que ambas inscripciones son de transmisión manuscrita. Junto al ya mencionado tomolo, contamos con otros 2 ejemplos de confusión en sílaba postónica: insola [m] por insula[m] (V6, s.VI) y Cordoba por Corduba (SE 5, s. VII). Carnoy $^{36}$ señala que en estas formas, además de la confusión de timbre, pudieron

${ }^{32}$ Sobre este fenómeno: Carnoy 1983: §§ 7-12; Grandgent 1991: § 208 y 243-244; Mariner 1952: 25 27; Leumann 1977: §57; Bassols 1981: §161; Väänänen 1985: §§ 54-56.

${ }_{33}$ Carnoy 1983: 48-51.

${ }^{34}$ Cabe señalar que esta es la única inscripción de Hispania donde aparece el término tomolo en lugar de tumulo, mientras que en la Galia se enmarcan 40 de los 48 casos recogidos en la Epigraphic Database Heidelberg para todas las provincias. Sobre esta variación entre una provincia y otra cf. Gaeng 1968: 87-88.

${ }^{35}$ En opinión de Mariner, la forma octubres sería un dialectismo de influjo osco (1952: 62-63).

${ }^{36}$ Carnoy 1983: 56-60. 
influir otros factores: la asimilación a la sílaba tónica en el caso de Cordoba y tomolo, y la confusión entre los sufijos -olus y-ulus, en el caso de insola[m].

\subsection{Tratamiento de vocales en hiato ${ }^{37}$}

Para intentar evitar el hiato (encuentro de dos vocales en el interior de una palabra pertenecientes a sílabas diferentes), la lengua latina desarrolló diferentes mecanismos en distintas épocas: la contracción de las vocales, el desarrollo de un sonido de transición entre ambas vocales (también llamado "Gleitlaut" o "glide"), la diptongación y la consonantización de una de las vocales. La contracción de vocales del mismo timbre fue corriente a lo largo de toda la historia del latín, sin que contemos en nuestros carmina con ningún caso significativo ni digno de mención. Sí es destacable el segundo mecanismo, la pronunciación de una y o una $w$ como sonido de transición entre ambas vocales, que a veces quedaba reflejada gráficamente ${ }^{38}$. En nuestro corpus contamos con dos ejemplos de este fenómeno, la forma fluuit en lugar de fluit, que se encuentra en un grafito de la Cueva Negra (MUCN 37) datado entre los ss II y III, y puuella ${ }^{39}$ por puella en una inscripción de la misma fecha del conuentus Cordubensis (J12).

Pero el mecanismo que ha tenido una mayor influencia en la evolución del latín a las lenguas romances es la consonantización. Para evitar el hiato, la $\breve{~ y ~ l a ~}$ $\check{e}$ latinas tendían a cerrarse ante una vocal más abierta, dando como resultado en ambos casos (con el paso previo de $e$ a $i$ ) una $y$. Ello provocó confusiones en la grafía entre la $i$ y la $e$, de las que tenemos algún ejemplo en nuestros carmina. En el grafito MUCN30, que no ha podido ser fechado, aparecen las formas gaudiat y gaudiant por gaudeat y gaudeant, con cierre de la $e$ en $i$ y consonantización de ésta, ya que ambas formas están escandidas como bisilábicas. Quizá el poeta para encajar dichas formas en el verso se sirviera de esta licencia prosódica, ya utilizada por los poetas clásicos y que parece tener su origen en este fenómeno fonético, que permitía contabilizar o no las semivocales $y$ e $w$, según las necesidades métricas. La consonantización de vocales en hiato fue aumentando en la poesía posterior, lo que puede responder a que esta pronunciación estaba cada vez más asentada $^{40}$. La grafía inversa, $e$ por $i$, la hallamos en una inscripción de Évora, EVO3, perteneciente al s. VI, donde aparece noxsea por noxia.

${ }^{37}$ Sobre este fenómeno: Carnoy 1983: §5; Grandgent 1991: §224; Mariner 1952: 25; Leumann 1977: §139b; Väänänen 1985: §§ 74-77; Adams 2013: 113-118.

${ }^{38}$ Cf. Molero 1987-1988.

${ }^{39}$ Este término, unido a puuer, aparece también en una inscripción de Britania ( $A E$ 1997, 977).

${ }^{40}$ Cf. Mariner 1952: 129. 


\subsection{Epéntesis ${ }^{41}$}

La epéntesis es un fenómeno fonético consistente en el desarrollo de una vocal de apoyo entre dos consonantes, siendo habitualmente la segunda una líquida o nasal. En la epigrafía hispana contamos con numerosos ejemplos de epéntesis, especialmente en nombres bárbaros ${ }^{42}$. Sin embargo, su número es muy reducido en los CLE, donde hallamos únicamente cuatro: discipulina, icenes, Asculepi y abistulerunt ${ }^{43}$.

La forma discipulina, que se encuentra en una inscripción de Tarragona del s. III (T9), está atestiguada ya en Plauto ${ }^{44}$. Derivada del termino discipulus, sufriría la síncopa de la $\breve{u}$, pretónica y en contacto con sonante, es decir, con las circunstancias propicias para la caída de una vocal ${ }^{45}$. En el habla popular, la tendencia a la epéntesis pudo contribuir a la recuperación de esta forma arcaica.

En un grafito de la Cueva Negra (MUCN10) datado en el s. I d. C. encontramos icenes. En esta forma se habría desarrollado una vocal epentética de timbre $e$, probablemente por asimilación a la sílaba siguiente, entre una oclusiva velar y una nasal ignes $>$ icenes. El desarrollo de una vocal de apoyo en la pronunciación del grupo gn no era raro ${ }^{46}$. En cuanto a la sustitución de la velar sonora por la velar sorda, podría atribuirse, en opinión de Hernánde ${ }^{47}$, a la neutralización de la oposición fonética entre ambas ante $n$, si no se trata de un simple error técnico de escritura. En este caso, a diferencia de lo que ocurría con discipulina, la vocal epentética no computa métricamente, por lo que su presencia podría deberse a un error del lapicida más que del poeta.

Igualmente extraña es la forma Asculepi, perteneciente también a un grafito de la Cueva Negra (MUCN14), fechado entre los ss. I-II d. C. Las formas habituales para denominar en latín al dios Esculapio eran Asclepius, forma culta derivada directamente del griego A $\sigma \kappa \lambda \eta \pi$ ıós, y Aesculapius, forma latina antigua, procedente del griego Ai $\sigma \kappa \lambda \alpha \pi \imath$ ś, caracterizada por la epéntesis ${ }^{48}$, fenómeno que era muy frecuente en la adaptación de los nombres griegos al latín en época antigua, mientras que en época clásica se preferían las transcripciones más

\footnotetext{
${ }^{41}$ Sobre este fenómeno: Carnoy 1983: 102-109; Leumann 1977: §§113-115; Mariner 1952: 29-30; Bassols 1981: $§ \S 193-196$.

${ }^{42}$ Cf. Carnoy 1983: 102-109.

${ }^{43}$ Mariner solo recoge el primero de estos ejemplos, discipulina; en cambio, incluye el término expectaraque (en lugar de spectraque), perteneciente al CLE 920, desechado de nuestro corpus por

${ }^{44}$ Plaut. As. 1, 3, 49; Ps. 5, 1, 30.

${ }^{45}$ Cf. Bassols 1981: $\$ 75$ y $§ 162-163$.

${ }^{46}$ Leumann (1977: 104) recoge ejemplos como digina o reginante.

${ }^{47}$ Hernández 2007: 293.

${ }^{48}$ Cf. Nieto 2009.
} recentior. 
rigurosas ${ }^{49}$. El término presente en nuestra inscripción es un hápax, que mostraría la inclusión de la vocal epentética también en la forma culta.

Del s. III es la inscripción LE6, en la que leemos la forma abistulerunt, a medio camino entre la epéntesis y la prótesis. Puesto que se trata del desarrollo de una vocal de apoyo entre dos consonantes en el interior de una palabra hemos de considerar que se trata de un caso de epéntesis, sin embargo, no se produce en el contexto habitual de este fenómeno. En efecto, en este caso la vocal epentética no se ha introducido ante líquida o nasal, sino ante una $-s$ seguida de consonante, es decir, el contexto en el que suele desarrollarse la vocal protética. Así pues, parece haberse producido una descomposición errónea del compuesto, al entenderse que $a b$ es el preverbio y stulerunt el verbo, introduciéndose la vocal $i$, timbre habitual de la vocal protética, entre ambos, como una "prótesis interna" 50 .

Carnoy señala que la vocal epentética en Hispania toma, casi sin excepción, el timbre de la vocal adyacente ${ }^{51}$. Podemos observar esta tendencia en icenes, pero no en discipulina, Asculepi y abistulerunt. No obstante, en discipulina no extraña el timbre $u$ de la vocal, pues es el que presentaba la forma originaria, sin sincopar; en Asculepi, la $u$ puede deberse a la influencia de la forma antigua Aesculapi, donde la $l$ es velar y provoca que la vocal epentética adquiera el timbre $u^{52}$; mientras que en abistulerunt la presencia de la vocal $i$ podría achacarse, como ya hemos señalado, al hecho de ir seguida de $s+$ consonante.

\subsection{Prótesis ${ }^{53}$}

La prótesis es un fenómeno fonético-sintáctico consistente en el desarrollo de una vocal $i$, con menor frecuencia una $e$, en palabras iniciadas por el grupo $s+$ consonante y precedidas, normalmente, de términos acabados en consonante. Este fenómeno se da, en un principio, en la transcripción de palabras griegas; así el primer ejemplo que conservamos, procedente de Pompeya es Ismurna = Smyrna (CIL 04, 7221). Posteriormente, hacia el s. II, empieza a extenderse a palabras latinas.

En Hispania uno de los primeros ejemplos de este fenómeno se da en la inscripción CIL II, 512954, hallada en Barcelona, en la que aparecen Iscolasticus e Ispumosus, que ha sido fechada en torno a la primera mitad del s. IV d. C.55

\footnotetext{
${ }^{49}$ Cf. Carnoy 1983: 103-104.

${ }^{50}$ En esta misma inscripción aparece también ispen.

${ }^{51}$ Carnoy 1983: 108.

${ }^{52}$ Cf. Bassols 1981: $\$ 194$.

${ }^{53}$ Sobre este fenómeno: Carnoy 1983: 110-113; Leumann 1977: §116; Mariner 1952: 30-33; Bassols 1981: §197; Väänänen 1985: §82.

${ }^{54}$ Bassols 1981: $\$ 197$.

${ }^{55}$ Gómez Pallarès 1997.
} 
Sin embargo, el estudio de los CLE de Hispania puede permitirnos adelantar la cronología.

Contamos en nuestros carmina con cuatro casos de vocal protética. El más antiguo, istas por stas, pertenece a un epitafio cordobés, CO13, de finales del s. II, del que sólo conservamos la parte derecha del texto, pero que, al estar compuesto a base de tópicos epigráficos estereotipados, ha podido ser restituido con bastante seguridad por parte de Fernández Martínez y Carande Herrero ${ }^{56}$. La línea 4 del fragmento conservado comienza con istas y, a la vista de diversos paralelos epigráficos, puede suponerse que delante de esta forma verbal se hallaría [tu qui]. De aceptar este supuesto nos encontraríamos ante el primer ejemplo conservado de vocal protética en la Península, confirmando así la hipótesis de Carnoy quien, a pesar de no haber hallado ningún ejemplo anterior al s. IV, conjeturaba que este fenómeno ya se daría en Hispania en el s. III $^{57}$. Sin embargo, el hecho de que la palabra que se encuentra delante de la prótesis acabe en vocal, qui, rompería la teoría del filólogo francés que, de acuerdo con el material que manejaba, suponía la aparición de la vocal protética solo tras un final consonántico o al comienzo del enunciado.

En una inscripción de Comeniaca (conuentus Asturum), LE6, datada en el s. III, encontramos un caso más de vocal protética: ispen. La vocal protética en spes está bien documentada, tanto en Hispania como fuera de ella ${ }^{58}$. En este caso tampoco va precedida la prótesis de una palabra acabada en consonante (in te ispen), por lo que podemos suponer que la vocal protética en Hispania no respondía ya a un fenómeno de sandhi, al contrario de lo que postulaba Carnoy.

Más tardíos, del s. VII, son dos ejemplos pertenecientes a sendas inscripciones de la Bética, ispiritum (CO75) e ispe (SE25). El primero aparece nuevamente tras un final vocálico (con[m]endo ispiritum ${ }^{59}$ ) en el subscriptum de la inscripción. El segundo, por su parte, se encuentra en una inscripción de transmisión manuscrita y, en este caso, no se computa métricamente la vocal protética, por lo que su inclusión se habría debido a un error del lapicida o del amanuense, y no del poeta $^{60}$. La prótesis está aquí en comienzo de verso.

El estudio de los CLE hispanos nos permite, por tanto, poder adelantar en un siglo la aparición de la vocal protética en nuestra Península (finales del s. II), así como suponer que su utilización, al menos a partir del s. III, no estaba sujeta a un principio de eufonía, pues aparece tanto después de un final vocálico y

\footnotetext{
${ }^{56}$ Carande-Fernández 2006 y CLEB: 184 -186.

${ }^{57}$ Carnoy, 1983: 110.

${ }^{58}$ Podemos señalar, entre otros, algunos ejemplos procedentes de Roma donde también aparece el término precedido de vocal, como Annia Ispes (AE 1973, 20) o Sabinillae fili(a)e Ispes (AE 1986, 42).

${ }^{59}$ Esta misma expresión con vocal protética (conmendauit ispiritum) aparece en una inscripción en prosa de Lusitania (IHC 2; ILCV 2409; ICERV86).

${ }^{60}$ Mariner 1952: 30.
} 
al comienzo del enunciado como después de un final consonántico. En cuanto al timbre de la vocal protética, cabe señalar que nuestros cuatro ejemplos se adecuan a lo ya señalado por Carnoy: el timbre de la vocal protética en Hispania es, casi sin excepción, $i^{61}$, lo que es esperable de acuerdo al punto de articulación de la $s^{62}$

\section{Diptongos}

\subsection{Monoptongación de $a e$ en $e$ y ultracorrecciones ${ }^{63}$}

La lengua latina tendió siempre a la monoptongación de los diptongos, respondiendo a una fuerte propensión a la asimilación (de apertura o de punto de articulación) de las dos vocales que lo constituían ${ }^{64}$. Así, de los seis diptongos breves del indoeuropeo únicamente quedaron en latín clásico tres: $a e, o e, a u, y$ en el habla vulgar se monoptongaron también los dos primeros. El diptongo ae evolucionó, debido a la asimilación recíproca de los dos elementos, hacia una $\bar{e}$ abierta, fonema nuevo en latín, donde las vocales largas y cerradas se oponían a las breves y abiertas. Ello provocó que este diptongo fuera sustituido a veces por $\bar{e}$, con predominio de la cantidad, y otras veces por $\breve{e}$, con predominio del grado de apertura. Tras la pérdida de la cantidad, el timbre pasó a ser el rasgo dominante y la confusión gráfica se decantó definitivamente hacia una $e$ abierta $^{65}$.

A la hora de estudiar la monoptongación de ae en los CLE de Hispania cabe centrarse en los siguientes aspectos: en qué fecha y lugar se produce el fenómeno, si se da de manera total o parcial en la inscripción y si el resultado es una $\breve{e}$ o una $\bar{e}$, es decir, si prevalece el timbre o la cantidad. En la siguiente tabla puede observarse la fecha y la provincia a la que pertenecen los CLE de Hispania en los que se da la monoptongación de manera parcial o total y en los que se produce una ultracorrección (ae en lugar de e). No se incluyen las inscripciones en las que el único término monoptongado es $e r a^{66}$, al considerar que se trata de una palabra fosilizada ${ }^{67}$.

\footnotetext{
${ }^{61}$ Carnoy, 1983: 110 .

${ }^{62}$ A estas mismas conclusiones llega Gaeng (1968: 265-266) en su estudio de las inscripciones cristianas procedentes de Roma: la vocal protética aparece tanto después de consonante como después de vocal o pausa y es siempre una $i$.

${ }^{63}$ Sobre este fenómeno: Leumann 1977: §§76-78; Mariner 1952: 10-17; Carnoy 1983: 70-81; Grandgent 1991: §§173-175: §§209-210; Väänänen 1985: §59; Bassols 1981: §97: §100 y §108; Coleman 1971; Fernández 1987-1988; Adams 2013: 71-81.

${ }^{64}$ Monteil 1992: 132.

${ }^{65}$ Cf. Fernández 1987-1988.

${ }^{66}$ Estas inscripciones son: SE5, SE7, SE30, SE13 y CO18 en la Bética, y VIS1 y SET1 en la Lusitania.

${ }^{67}$ A este respecto, es muy reveladora una inscripción de nuestro corpus, SE7, en la que aparece aera, con el diptongo conservado, en el carmen, y era, con monoptongación, en la datación.
} 


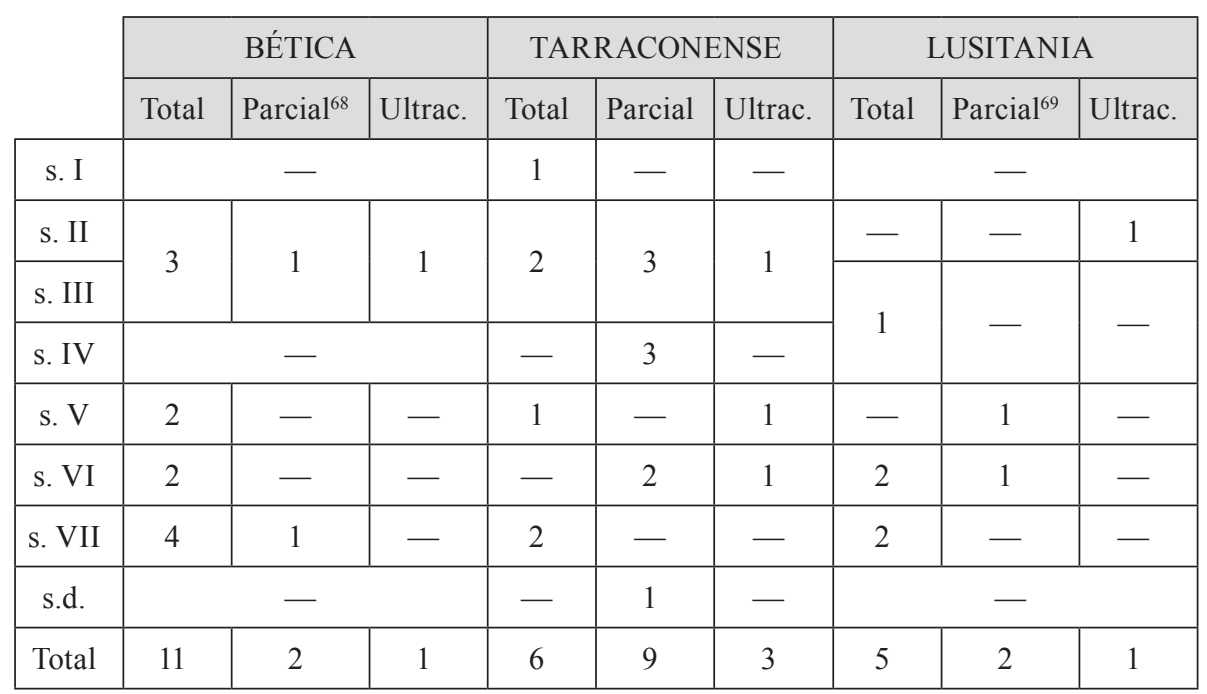

Como ya señalaba $\mathrm{Mariner}^{70}, \mathrm{y}$ anteriormente $\mathrm{Carnoy}^{71}$, las inscripciones con vacilaciones entre las grafías ae y $e$ son escasas en la Bética y la Lusitania, especialmente en los lugares más romanizados, y predominantes en la Tarraconense.

La Bética cuenta con 13 inscripciones con monoptongaciones de $a e$ en $e$ y en $11^{72}$ de estas inscripciones ( $85 \%$ ), la monoptongación es total, aunque en cinco $^{73}$ de ellas solo hay un caso de monoptongación. Las otras dos inscripciones, SE17 y CO21B, presentan cierta vacilación, pues en unos términos aparece el diptongo monoptongado y en otros no. El estudio de la monoptongación en SE17 (c. s. II) es complicado, al tratarse de una inscripción de tradición manuscrita con versiones distintas según la fuente ${ }^{74} \mathrm{y}$ en las que ha podido haber interferencias de los amanuenses. Siguiendo la versión mayoritaria, tendríamos el diptongo mantenido en el nombre propio Laelius y monoptongado en precipiti, pero deben tomarse estos datos con suma cautela. También de transmisión manuscrita es CO21B, datada en el s. VII, donde únicamente se mantiene el diptongo en haec, quizás por ser

${ }^{68}$ Mariner (1952: 12) incluye entre las inscripciones de la Bética en las que se da la monoptongación parcial CO7, en cuyo praescriptum aparece Melitine, considerándolo dativo; sin embargo, no hay motivos que impidan considerar que se trata de un nominativo.

${ }^{69}$ Mariner (1952: 13) incluye también BE1, considerando, al igual que Carnoy (1983: 72), que el que que aparece en la línea 6 es un pronombre relativo monoptongado. Sin embargo, para que el pronombre relativo encajara en la oración debería ir en acusativo, quam, por lo que preferimos pensar que se trata de la conjunción enclítica.

${ }^{70}$ Mariner 1952: 12.

${ }^{71}$ Carnoy 1983: 77-78.

72 SE1 (ss. II-III); CO13 (ss. II-III); J12 (ss. II-III); SE16 (s. V); SE23 (ss. V-VII); SE28 (ss. VI-VII); CO20 (ss. VI-VII); CA4 (s. VII); HU1 (s. VII); HU4 (s. VII); SE25 (s. VII).

${ }^{73} \mathrm{CO} 13, \mathrm{~J} 12$, SE16, SE28 y CO20.

${ }^{74}$ CLEBES: 57-64. 
un demostrativo muy usado, mientras que se encuentra monoptongado en precipitur, predo y cede, además de en el fosilizado era. No son, por tanto, casos muy significativos.

En la Lusitania, únicamente dos inscripciones (29\%) no presentan monoptongación total, BA13 y BA4. En ambos casos la palabra no monoptongada es saeculum, lo que en opinión de Mariner podría tratarse de una corrección insconsciente del copista erudito ${ }^{75}$. La primera es una inscripción cristiana del s. V donde frente a saecula aparece precepit y patrie. En BA4, inscripción cristiana del s. VII, aparece precisa, secula y celestia en oposición a saeculorum.

En la Tarraconense, a diferencia de lo que ocurría en la Bética y la Lusitania, son minoritarias las inscripciones en las que todos los diptongos aparecen monoptongados: únicamente en seis ${ }^{76}$ inscripciones (40\%), y sólo en $\operatorname{dos}^{77}$ de ellas hay más de un caso. En otras nueve inscripciones (60\%) existe cierta vacilación a la ahora de escribir el diptongo, apareciendo en algunos términos ae y en otros $e$, sin que haya, en la mayoría de los casos, un motivo para ello ${ }^{78}$. En T3, inscripción datada entre finales del s. II y principios del s. III, se encuentra aerarius en oposición a queram y lacrime. De la misma época es CU1, donde aparece aurige frente a saepe ${ }^{79}$. Raro es el caso de T9 (s. III), que presenta hec frente a suae, paene, aetate y haec, por lo que podría pensarse que quizá la monoptongación en hec fuera más bien un olvido de la $a$ o de un nexo por parte del lapicida. En LE7 (ss. III-IV) y T23 (s. IV) aparece aet[---] y aeternus frente a uite y peregrine respectivamente, lo que podría achacarse a una mayor propensión a $e$ en sílaba final átona ${ }^{80}$. Ya cristianas, del s. VI, son V6 y CU3, donde predomina la grafía monoptongada, intercalada con algún caso de grafía correcta. En V6, inscripción de transmisión manuscrita, se encuentra caelebs frente a preclarus, predicans, sepsit, predulcem, presentis y uite. En CU3 (s. VI) la vacilación se da incluso dentro de una misma palabra: etheriae. Se produce también en esta inscripción una confusión entre verbos ya homófonos, queror y quaero, apareciendo querunt por quaerunt y quaeritur por queritur. Por último, un grafito de la Cueva Negra (MUCN30), cuya fecha se desconoce, presenta eum por aeuum, junto a guttae (donde el diptongo está escandido como breve), nymphae y saepe.

En T26, inscripción cristiana del s. IV, la monoptongación es dudosa, pues aparece el diptongo escrito correctamente en todos los términos salvo en dulcissime (1. 8: filiae dulcissime quae uixit anno). Por ello, aunque como se ha visto no

\footnotetext{
${ }^{75}$ Mariner 1952: 13.

${ }^{76}$ GI2 (s. I), T19 (ss. II-III), LE6 (s. III), V8 (ss. V-VI), V2 (s. VII) y TO5 (s. VII).

${ }^{77}$ LE6 y TO5.

${ }^{78}$ Mariner 1952: 13.

${ }^{79}$ Mariner (1952: 13) opina que la grafía $e$ en aurige puede deberse a la falta de espacio, si bien, como señala Del Hoyo (ficha CU1 preparada para el fascículo 2 del volumen XVIII del CIL), el lapicida podría haber optado por un nexo, al igual que hace en $s a^{\wedge} e p e$.

${ }^{80}$ Mariner 1952: 13.
} 
sería raro encontrar esta vacilación dentro de una misma inscripción, podría pensarse que se trata de un adverbio que modifica a uixit.

En cuanto a la cronología, el primer ejemplo de monoptongación en los CLE hispanos pertenece a la inscripción GI2, donde aparece tres veces el nombre propio Leli (por Laeli). Esta inscripción, si bien fue situada en la época de Augusto por parte de F. Fita ${ }^{81}$, podría fecharse, según el último trabajo sobre las termas de Caldes de Malavella ${ }^{82}$, en la segunda mitad del s. I d. C., fecha que encajaría con el tipo de metro empleado. Esta datación apoyaría la hipótesis de Carnoy ${ }^{83}$, según la cual los primeros ejemplos de monoptongación se darían en Hispania a finales del s. I, haciéndose más numerosos a partir del s. II. Por otra parte, no hay un límite cronológico entre las inscripciones que presentan cierta vacilación a la hora de representar el diptongo y aquellas en las que aparecen todos los diptongos monoptongados: como puede observarse en la tabla, hay inscripciones del s. II donde la monoptongación se da en todos los casos y otras del s. VII donde algunos casos aparecen monoptongados y otros no. En opinión de Mariner ${ }^{84}$, este hecho podría deberse a que la vacilación responde en muchos casos al desconocimiento de la ortografía por parte del compositor.

Desde el punto de vista métrico, la e resultante de la monoptongación es, en la mayoría de los casos, escandida como larga, tanto en las inscripciones de fecha temprana, como GI2, en las que todavía se conservaba la cantidad, como en inscripciones tardías, como CA4 (s. VII), donde las diferencias cuantitativas ya se habrían perdido pero se mantendrían las cantidades en las composiciones poéticas por imitación de la métrica clásica. Sólo en dos inscripciones, VIS2 y T23, la $e$ resultante de la monoptongación podría ser escandida como breve. La inscripción VIS2, perteneciente al conuentus Scallabitanus y fechada entre los ss. III y IV, presenta el siguiente pentámetro: hic sedis hic terr(a) hic tib(i) eterna domus, correcto si se escande la e- inicial de eterna como breve. El caso de T23, inscripción perteneciente al conuentus Tarraconensis y fechada en el s. IV, es más dudoso. Se trata de una inscripción fragmentaria de la que sólo se conservan los finales de línea, que parecen ser finales hexamétricos, aunque no hay ni una sola cláusula cuantitativa correcta. En la línea 3 aparece [pere]grine sepulcrum, cláusula correcta si se escande la -e de peregrine como breve, y en la línea 5, concessit aeternus, correcta si se escande el diptongo como breve. No obstante, las incorrecciones del resto de las cláusulas parecen indicar que se trata ya de hexámetros a medio camino entre la métrica cuantitativa y acentuativa, donde hay sílabas largas que por ser átonas ocupan el lugar de las breves.

\footnotetext{
${ }^{81}$ Fita 1904.

${ }^{82}$ Merino - Nolla - Santos 1994.

${ }^{83}$ Carnoy 1983: 77.

${ }^{84}$ Mariner 1953: 13.
} 
En cuanto a los casos de ultracorrección, el más antiguo pertenece a la Lusitania, a una inscripción del s. II, BA15, donde aparece el imperativo edae en lugar de ede. Un poco más tardío es el ejemplo de la Bética, adsiduae por adsidue, perteneciente a la inscripción CO7, fechada entre los ss. II y III. Por último, la Tarraconense cuenta con tres ejemplos de ultracorrección: Praepusa ${ }^{85}$ (L1, ss. II-III), praetioso (AST3, ss. V-VI) y el ya mencionado quaeritur (CU3, s. VI).

Estos ejemplos confirmarían la hipótesis propuesta por Carnoy ${ }^{86}$ : en Hispania es siempre una $\breve{e}$ la que es reemplazada por el diptongo ae, hecho que demostraría que esa $e$ tenía un sonido abierto, como la ĕ. En el caso de Praepusa, ae reemplaza a una épsilon, que era cerrada en griego, pero es probable que en Roma ese sonido se igualara a su $\breve{e}$ abierta. El único ejemplo en el que ae aparece en lugar de una $\bar{e}$ es en sílaba final, en adsiduae, posición en la que la distinción entre los timbres era menor, confluyendo tanto la $\breve{e}$ como la $\bar{e}$ en una sola $e$.

\subsection{Monoptongación de oe en $e^{87}$}

El resultado de la monoptongación de oe, en cambio, fue un fonema ya existente en latín, una $\bar{e}$ cerrada. Este hecho provocó que se produjeran menos vacilaciones gráficas y fonéticas. En nuestro corpus únicamente contamos con cinco ejemplos repartidos en cuatro inscripciones tardías: penarum por poenarum (B2a, ss. IV-V), cenobium por coenobium (T17, s. VI), cetibus por coetibus (TO5, s. VII), cenobio por coenobio y cetu por coetu (CA4, s. VII). Se trata de inscripciones cristianas, donde, como señalan Carnoy $^{88}$ y Mariner $^{89}$, la monoptongación es abundante. Desde el punto de vista métrico la $e$ resultante es, como cabría esperar, siempre escandida como larga.

\section{RECAPITULACIÓN}

El estudio de los aspectos más importantes de la grafía, el vocalismo y los diptongos de los CLE de Hispania nos ha servido, en algunos casos, para apoyar con nuevos datos las teorías postuladas anteriormente; en otros, para aportar novedades importantes sobre algunos de los fenómenos tratados. No está de más hacer una somera recapitulación de las principales conclusiones extraídas a partir de su estudio.

${ }^{85}$ Se transcribe como un diptongo la épsilon griega.

${ }^{86}$ Carnoy 1983: 75-76.

${ }^{87}$ Sobre este fenómeno: Leumann 1977: $\S \S 79-80$; Mariner 1952: 17-18; Carnoy 1983: 84-85; Grandgent 1991: §§173-175: §§209-210; Väänänen 1985: §59; Bassols 1981: §104 y §108.

${ }^{88}$ Carnoy 1902: 85 .

${ }^{89}$ Mariner 1952: 18. 


\subsection{Grafías}

- Representación de $\bar{\imath}$ mediante el dígrafo ei: Mariner sostenía que este dígrafo se utilizaría en nuestros carmina únicamente para marcar la $\bar{l}$ etimológica en sílabas desinenciales, pero solo en uno de los cuatro carmina hispanos que contienen este fenómeno aparecidos tras la publicación de su obra se cumple esta norma. No obstante, la cronología temprana (MU13B, s. I a. C.) o tardía (J7 y T8, ss. I-II d. C.) de estas inscripciones invita a pensar que esta tendencia postulada por Mariner comenzaría a extenderse en Hispania en el s. I a. C. siendo utilizada hasta finales del s. I d. C.

- Adaptación de los fonemas griegos al latín (la y y las aspiradas): hemos podido comprobar que en los CLE hispanos predominan las grafías consideradas cultas. Si bien, los casos más interesantes que nos ofrecen nuestras inscripciones son aquellos en los que se mezclan dos grafías posibles, muestra de la vacilación a la hora de utilizar una u otra grafía en el período de

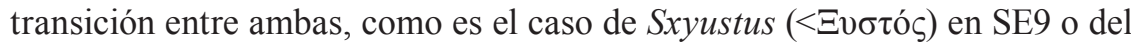
doblete Torax / Thoracis de MU7.

\subsection{Vocalismo simple}

Las principales aportaciones de nuestro estudio en el campo del vocalismo son las relativas a la prótesis, la epéntesis y el hiato.

- Prótesis: el estudio de este fenómeno en los CLE ha resultado de vital importancia. Por un lado nos permite adelantar la fecha de aparición de la vocal protética en Hispania, ya que contamos con un posible caso fechado a finales del s. II (CO13) y uno perteneciente a una inscripción del s. III (LE 6) mientras que la inscripción CIL II, 5129, que estaba considerada como el documento más antiguo de vocal protética en Hispania, está fechada en torno a la primera mitad del s. IV d. C. Por otro, podemos suponer, a partir de los nuevos hallazgos, que su utilización, al menos a partir del s. III, no estaba sujeta a un principio de eufonía, al contrario de lo que conjeturaba Carnoy.

- Tratamiento de vocales en hiato: nuestros carmina nos ofrecen nuevos ejemplos interesantes sobre los métodos empleados para evitar el hiato en Hispania. Carnoy $^{90}$ y Mariner ${ }^{91}$ tratan en sus estudios sobre la lengua de las inscripciones hispanas los cambios entre $i$ y $e$ en posición de hiato, si bien en los CLE estudiados hallamos ejemplos de otros fenómenos relativos al hiato dignos de mención: el desarrollo de un sonido de transición o glide (fluuit por fluit en MUCN 37, datado entre los ss. II y III; y puuella por puella en una inscripción

\footnotetext{
${ }^{90}$ Carnoy 1983: $§ 5$.

${ }^{91}$ Mariner 1952: 25.
} 
de la misma fecha, J12) y la utilización de la $h$ en pihi (SE1, ss. II-III) como marca preventiva para evitar la contracción.

- Epéntesis: en lo referente a este fenómeno es relevante la forma Asculepi (MUCN14), hápax para denominar al dios Esculapio, que muestra la inclusión de la vocal epentética en su forma culta, Asclepius.

\subsection{Diptongos}

En cuanto a los diptongos, los nuevos hallazgos sirven para apoyar las hipótesis de filólogos anteriores, especialmente en el caso de ae, pues contamos con una gran cantidad de ejemplos de monoptongación y ultracorrección ${ }^{92}$. Así, hemos podido constatar lo que ya apuntaban Carnoy y Mariner:

- Los primeros ejemplos de monoptongación se darían en Hispania a finales del s. I, haciéndose más numerosos a partir del s. II.

- Las inscripciones que presentan vacilaciones entre las grafías ae y $e$ son escasas en la Bética y la Lusitania, y predominantes en la Tarraconense.

- No hay un límite cronológico entre las inscripciones que presentan cierta vacilación a la hora de representar el diptongo y aquéllas en las que aparecen todos los diptongos monoptongados.

- La e resultante de la monoptongación es, salvo en dos casos, escandida como larga, tanto en inscripciones de fecha temprana como en inscripciones tardías, donde la cantidad ya se habría perdido pero se seguiría imitando la métrica clásica.

- En cambio, ya desde el s. II, es siempre una $\breve{e}$ la que es reemplazada por el diptongo $a e$, hecho que demostraría que esa $e$ tenía un sonido abierto.

Es evidente, pues, que el análisis de los fenómenos lingüísticos que aparecen en las inscripciones latinas es una fuente de información fundamental para el estudio de la evolución del latín en las diferentes provincias. El hecho de que se trate de un corpus abierto, puesto que el número de inscripciones conocidas aumenta incesantemente, hace necesaria una serie de actualizaciones que permita ofrecer nuevos datos, no solo desde el punto de vista lingüístico, sino también en otros campos como la métrica o la literatura.

${ }^{92}$ Los casos de monoptongación y ultracorrección son también muy abundantes en el resto de provincias, como por ejemplo en la Galia o en Italia (cf. Pirson 1901: 18-21 o Gaeng 1968: 241-252). 
ÍNDICE DE CORRESPONDENCIAS CON OTRAS COLECCIONES EPIGRÁFICAS

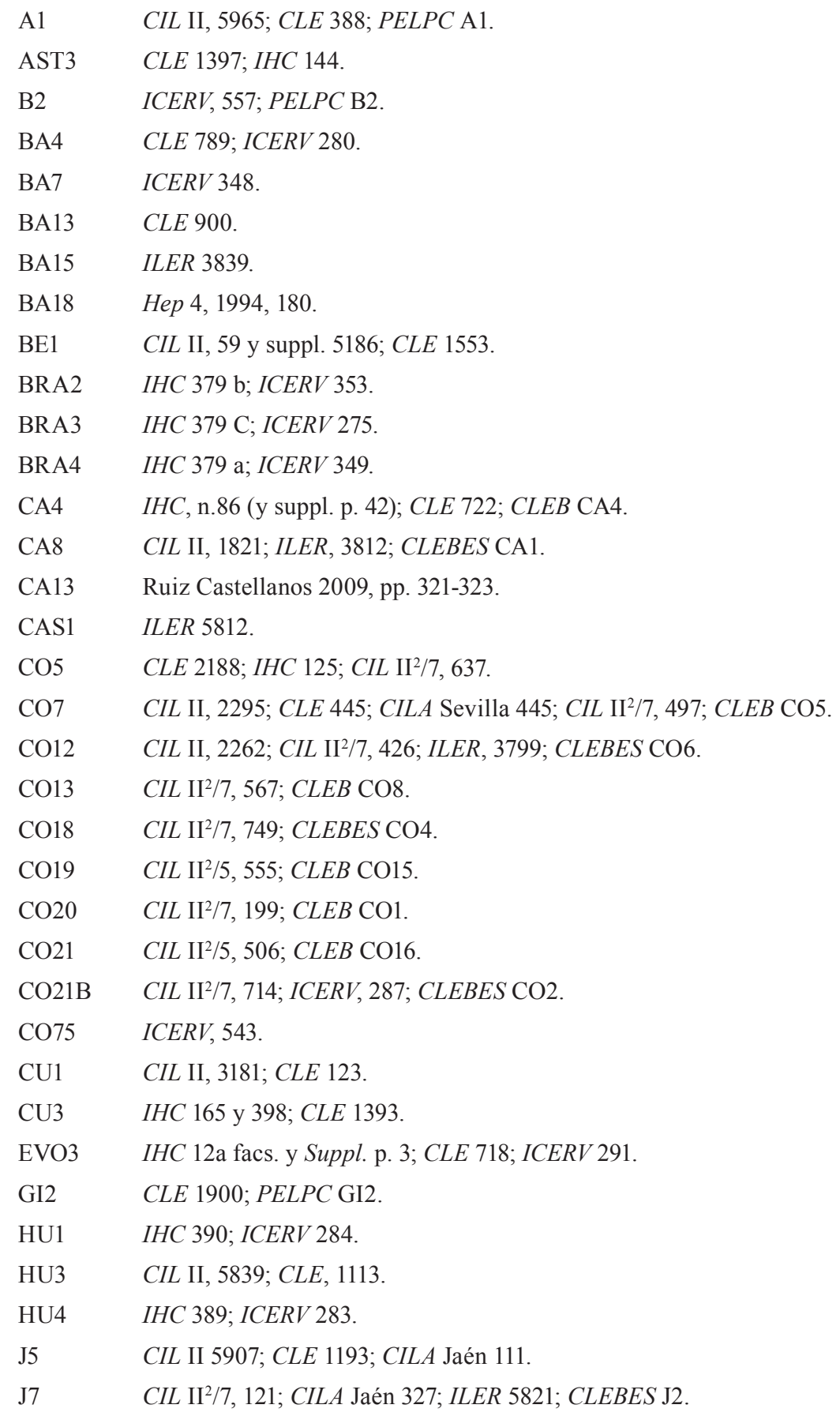


$\mathrm{J} 12 \quad C I L \mathrm{II}^{2} / 7,22 ; C L E B \mathrm{~J} 12$.

L1 PELPC L1.

LE6 ILER 5811; AE 1957, 37.

LE7 CLE 1986.

MU3 CLE 1076; CLECN 8.

MU7 CIL II 3475; CLE 980; ILER 5775; CLECN 3.

MU8 CIL II 3453; CLE 1194; CLECN 10.

MU12 CIL II 3495, add. p. 952; ad CLE 58; CLECN 1.

MU13 ILER 5776; CIL I², 3449g; CLECN 2.

MU13B CLECN 4.

MU20 CIL II, 3479; CLE 979; CLECN 7.

MUCN4 Stylow - Mayer 1996, pp. 211-212.

MUCN10 Stylow - Mayer 1996, pp. 204-205.

MUCN11 Stylow - Mayer 1996, pp. 206-208.

MUCN13 Stylow - Mayer 1996, pp. 197-198.

MUCN14 Stylow - Mayer 1996, pp. 198-204.

MUCN30 Stylow - Mayer 1996, p. 210.

MUCN37 Stylow - Mayer 1996, pp. 218-220.

SE1 CIL II 1088; CLE 541; CILA Sevilla 305; CLEB SE1.

SE2 CIL II, 1094; CILA Sevilla, 304; ILER, 5799-5800; CLEBES SE7.

SE5 CILA Sevilla 1031; CLEB SE3.

SE7 IHC 363; CILA Sevilla 606; CLEB SE5.

SE9 CILA Sevilla 759; $C I L \mathrm{II}^{2} / 5,1227$; $C L E B$ SE14.

SE12 CILA Sevilla 1013; CLEB SE12.

SE13 CILA Sevilla 1039; CLEB SE8.

SE15 CIL II, 1399; CILA Sevilla 827; ILER, 5793; CLEBES SE2.

SE16 CILA Sevilla 1013; CLEB SE12.

SE17 CIL II, 1413; CLE 1069; CILA Sevilla 622; CIL II²/5, 1055; CLEBES SE5.

SE23 CILA Sevilla 175; CLEB SE10.

SE25 IHC 362; CLEBES SE1.

SE28 IHC 361; CLEBES SE8.

SE29 IHC 361c; CLEBES SE10.

SE30 CLE 1392; IHC 65; CILA Sevilla 154; CLEB SE6.

T3 RIT 441; PELPC T3.

T6 CIL II, 4350; CLE 235; RIT 541; PELPC T6.

T7 CIL II, 4314; CLE 1279; CIDER 17; RIT 444; PELPC T7. 
T8 CIL II $2 / 14,814 ;$ PELPC T8.

T9 RIT 447; PELPC T9.

T11 CLE 2180; RIT 901; PELPC T11.

T15 ICERV 295; RIT 969; PELPC T15.

T17 IHC 413; RIT 939; PELPC T17.

T18 IHC 413; CLE 699; RIT 938; PELPC T18.

T19 CIL II, 4379; CLE 122; RIT 605; PELPC T19.

T22 RIT 924; PELPC T22.

T23 RIT 1004; ICERV 298; PELPC T23.

T24 CIL II, 4428; CLE 981; RIT 695; PELPC T24.

T26 RIT 955; ICERV 297; PELPC T26.

TO2 IHC $391\left(=73^{*}\right) ;$ ICERV 361 .

TO3 Martín Valls 1971.

TO5 IHC 158 (y suppl. 74); CLE 724.

SET1 IHC 1; ICERV 311.

V2 CIL II ${ }^{2} / 14,90 ;$ PELPC V2.

V4 CIL II, 3871; CLE 978; CIL II²/14, 347; PELPC V4.

V6 IHC 409; $C I L \mathrm{II}^{2} / 14,89 ;$ PELPC V6.

V8 CIL II ${ }^{2} / 14,92 ;$ PELPC V8.

VIS1 IHC 21; CLE 717; ICERV 85.

VIS2 Leal Soares 1992.

REFERENCIAS BIBLIOGRÁFICAS

Adams $2013=$ J. N. Adams, Social Variation and the Latin Language (Cambridge 2013).

Bassols 1981 = M. Bassols, Fonética latina (Madrid $1981=1962)$.

Carande-Fernández $2006=$ R. Carande Herrero y C. Fernández Martínez, “CIL II2/7,567: Notas filológicas a un carmen cordobés”, en M. Rodríguez-Pantoja (ed.), Las raíces clásicas de Andalucía. Actas del IV Congreso Andaluz de Estudios Clásicos (Córdoba 2006) I, 391-403.

Carnoy 1983 = A. Carnoy, Le latin d'Espagne d'après les inscriptions. Étude linguistique (Hildesheim-New York 1983 = 1906).

CILA Jaén = C. González Román y J. Mangas Manjarrés, Corpus de Inscripciones Latinas de Andalucía, vol. III: Jaén (Sevilla 1991).

CILA Sevilla = J. González Fernández, Corpus de Inscripciones Latinas de Andalucía, vol. II (Tomos I-IV): Sevilla (Sevilla 1991).

$C L E=$ F. Bücheler y E. Lommatzsch, Carmina Latina Epigraphica (Stuttgart 1982). 
CLEB $=$ C. Fernández Martínez, Carmina Latina Epigraphica de la Bética Romana. Las primeras piedras de nuestra poesía (Sevilla 2007).

CLEBES = J. Martín Camacho, Carmina Latina Epigraphica Baeticae ex Schedis: edición y comentario (Sevilla 2010).

$C L E C N=\mathrm{X}$. Gómez Font y R. Hernández Pérez, Carmina Latina Epigraphica Carthaginis Nouae (Valencia 2006).

Coleman $1971=$ J. Coleman, "The monophthongization of/ae/ and the vulgar latin vowel system", Transactions of the Philological Society 70 (1971) 175-191.

Fernández 1987-88 = C. Fernández Martínez, "Monoptongación de ae y nuevo sistema vocálico", Habis 18-19 (1987-88) 155-160.

Fita 1904 = F. Fita, "Nuevas inscripciones romanas de Caldes de Malavella, Herramélluri y Astorga", BRAH 44 (1904) 86-87.

Gaeng 1968 = P. A. Gaeng, An inquiry into local variations in vulgar Latin: as reflected in the vocalism of Christian inscriptions (Chapel Hill 1968).

Gómez Pallarès 1997 = J. Gómez Pallarès, Edición y comentario de las inscripciones sobre mosaico de Hispania. Inscripciones no cristianas (Roma 1997).

Grandgent $1991=$ C. A. Grandgent, Introducción al latín vulgar, trad. esp. de F. de B. Moll (Madrid $1991=1928)$.

Hernández 2007 = R. Hernández Pérez, "Los tituli picti métricos de la Cueva Negra de Fortuna (Murcia)" Epigraphica LXIX (2007) 287-320.

$I C E R V=\mathrm{J}$. Vives, Inscripciones cristianas de la España romana y visigoda (Barcelona 1969).

$I H C=$ E. Hübner, Inscriptiones Hispaniae Christianae (Berlin 1871).

ILER = J. Vives, Inscripciones latinas de la España romana (Barcelona 1971-72).

Leal Soares 1992 = C. I. Leal Soares, "Vincitur hic fatus - O epitáfio métrico de Couto de Baixo", Conimbriga 31 (1992) 155-172.

Leumann 1977 = M. Leumann, Lateinische Laut- und Formenlehre (München 1977).

Mariner 1952 = S. Mariner Bigorra, Inscripciones hispanas en verso (Madrid 1952).

Martín Valls 1971 = R. Martín Valls, "Inscripción romana del Bercial, Alcolea de Tajo (Toledo)", BSEAA 37 (1971) 425-429.

Martínez 1981 = E. Martínez Ortega, "El vocalismo de las inscripciones de la Bética", Gades 8 (1981) 197-220.

Merino - Nolla - Santos 1994 = J. Merino, J. Nolla y M. Santos, Aquae Calidae. Presència romana a la Selva (Santa Coloma de Farners 1994).

Molero 1987-1988 = L Molero Alcaraz, "Estudio de I, V consonánticas y su problemática gráfico-fonética en epígrafes latinos de época republicana”, Habis 18-19 (1987-1988) 127-154.

Monteil 1992 = P. Monteil, Elementos de Fonética y Morfología del latín, trad. esp. de C. Fernández Martínez (Sevilla 1992).

Moralejo 1972 = J. L. Moralejo, "Notas sobre la grafía Y en inscripciones latinas", CFC 4 (1972) 165-185. 


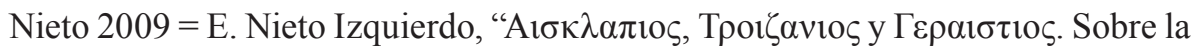
supuesta epéntesis de yod en la Argólide", GIF 61 (2009) 3-14.

Omentchenko 1977 = S. W. Omentchenko, A Quantitative and Comparative Study of the Vocalism of the Latin Inscriptions of North Africa, Britain, Dalmatia, and the Balkans (Chapel Hill 1977).

PELPC = J. Gómez pallarès, Poesia Epigràfica Llatina als Països Catalans. Edició i Comentari (Barcelona 2002).

Pirson 1901 = J. Pirson, La langue des inscriptions latines de la Gaule (Bruxelles 1901).

Purnelle 1989 = G. Purnelle, "La transcription des noms grecs dans les inscriptions latines: Le cas des aspirées", CILL 15, 1-4 (1989) 355-366.

Purnelle 1995 = G. Purnelle, Les usages des graveurs dans la notation d'upsilon et des phonèmes aspirés: le cas des anthroponymes grecs dans les inscriptions latines de Rome (Liège 1995).

$R I T=\mathrm{G}$. Alföldy, Die römischen Inschriften von Tarraco (Berlin 1975).

Stylow - Mayer 1996 = A. U. Stylow y M. Mayer, "Los tituli de la Cueva Negra. Lectura y comentarios literario y paleográfico", en El balneario romano y la Cueva Negra de Fortuna (Murcia). Homenaje al Prof. Ph. Rahtz, eds. A. González, M. Mayer, A.U. Stylow y R. González (Murcia 1996) 367-406.

Stylow 1995 = A. U. Stylow, "Los inicios de la epigrafía latina en la Bética. El ejemplo de la epigrafía funeraria", en Roma y el nacimiento de la cultura epigráfica en occidente, ed. F. Beltrán (Zaragoza, 1995 219-238.

Ruiz Castellanos 2009 = A. Ruiz Castellanos, "Dos médicos más en Gades", en: Espacios, usos y formas de la epigrafía Hispana en épocas Antigua y Tardoantigua. Homenaje al Dr. Armin U. Stylow (Mérida 2009) 319-322.

Väänänen 1985 = V. Väänänen, Introducción al latín vulgar, trad. esp. de Manuel Carrión (Madrid $1985=1967)$.

Zamboni 1965 = A. Zamboni, "Contributo allo studio del latino della X Regio Augustea (Venetia e Histria). Introduzione. Fonetica (Vocalismo)", AIV 124 (1965-66) 463-517

Zamboni 1967 = A. Zamboni, "Contributo allo studio del latino epigrafico della X Regio Augustea (Venetia e Histria). Fonetica (vocali in iato e consonantismo)", AIV 126 (1967-68) 77-129. 